\title{
Embodying Embodiment in a Structural, Macroeconomic Input-Output Model
}

\author{
Daniel J. Wilson* \\ Federal Reserve Bank of San Francisco
}

This draft: January 16, 2003

* This paper was adapted from Chapters 4 and 5 of my dissertation at the University of Maryland. Much of the research for this paper was conducted while I was a researcher at the INFORUM research center. I thank the staff of INFORUM, particularly Doug Meade, and its director (and my advisor) Clopper Almon for all of their support and advice. This paper also benefitted from helpful comments from participants at the $14^{\text {th }}$ International Input-Output Conference in Montreal. 


\begin{abstract}
:
In this paper, I develop a regression-based system of labor productivity equations which account for capital-embodied technological change and I incorporate this system into IDLIFT, a structural, macroeconomic input-output model of the U.S. economy. Builders of regressionbased forecasting models have long had difficulty finding labor productivity equations that exhibit the "Solowian" property that movements in investment should cause accompanying movements in labor productivity. The production theory developed by Solow and others dictates that this causation is driven by the effect of traditional capital deepening as well as technological change embodied in capital. Lack of measurement of the latter has hampered the ability of researchers to properly estimate the productivity-investment relationship. Recent research by Wilson (2001) has alleviated this difficulty by estimating industry-level embodied technological change. In this paper, I utilize those estimates to construct capital stocks adjusted for technological change and then use these adjusted stocks to estimate Solow-type labor productivity equations. It is shown that replacing IDLIFT's former productivity equations, based on changes in output and time trends, with the new equations results in a convergence between the dynamic behavior of the model and that predicted by traditional (Solowian) production theory.
\end{abstract}

Keywords: Equipment-Embodied Technological Change, Input-Output, Productivity, Forecasting JEL Codes: C3, C5, O3 


\section{Introduction}

The hypothesis that much of technological progress is embodied in new capital goods, and therefore investment in new capital is necessary to foster productivity growth, is an old one tracing its roots at least as far back as Smith's Wealth of Nations, which attributed its source to the division of labor: "The invention of all those machines by which labour is so much facilitated and abridged, seems to have been originally owing to the division of labour" (Smith, 1776, p.9). ${ }^{1}$ The basic hypothesis was refined and extended over time by Karl Marx, Joseph Schumpeter, and Robert Solow, among others. Yet, obtaining independent measures of the rate at which capitalembodied (or "investment-specific") technological change has progressed has long eluded us. Absent knowledge of this rate, it is impossible to correctly measure the productive capacity of the economy's capital stock.

The concept of the productive capacity of capital, or simply productive capital for short, is the theoretically correct concept of capital to be used in production and productivity analyses (according to traditional production theory). The productive capital stock, combined with information on the degree to which capital is being utilized, tells us the flow of capital services used in the production process. The flow of capital services to production is generally considered to be one of the main determinants of labor productivity. In particular, the production theory developed by Solow and others in the 1950's and 1960's assumes that labor and capital have some degree of complementarity so that increases in capital increase the productivity of labor. ${ }^{2}$

${ }^{1}$ See Scherer (1999), Chapters 2-4, for a discussion of the history of economic thought relating to technological change (particularly that which is embodied in machinery) and long-run productivity growth.

${ }^{2}$ Hereafter, this theory will be referred to as the "Solowian" production theory and labor productivity equations which exhibit the property of capital increases causing labor productivity 
Thus, modeling long-run labor productivity growth relies on good measures of productive capital (as well as utilization rates). And, of course, modeling long-run productivity growth is $a$, if not the, key element to any forecasting model.

Lamentably, good measures of productive capital are hard to come by, particularly at the industry-level. ${ }^{3}$ The lack of accurate measures of capital often forces economic modelers to choose between having a labor productivity equation in their model that is not based on traditional (Solow-type) production theory but fits the historical data well, and having a labor productivity equation modeled on production theory but which has a poor historical fit. For example, the IDLIFT forecasting model, which is a structural macroeconomic model of the U.S. economy with an input-output core, uses a labor productivity equation based primarily on time trends. Attempts in the past to incorporate a theoretically more appealing productivity equation into the model were unsuccessful, as the new equations did not fit the historical data well and often caused the forecast to be unstable.

This paper utilizes the results of recent work that attempts to quantify the quality (technological) change in capital and therefore accurately measure the productive capital stock. A number of recent papers have sought to infer the rate of equipment-embodied technological change from quality-adjusted investment price indices. ${ }^{4}$ Wilson (2001), on the other hand,

increases will be referred to as "Solow-type" equations.

${ }^{3}$ Unless otherwise indicated, capital will hereafter refer to productive capital as defined above.

${ }^{4}$ Greenwood, Hercowitz, and Krusell (1997) and Hornstein and Krusell (1996) are prominent examples of the price approach to quantifying embodied technological change. This price-side literature uses the growth rate in the relative price of investment (to consumption) to infer the rate of embodied technological change. For this approach to be valid, the relative price must fully and accurately account for quality improvements in investment (capital) goods. Wilson (2001) argues that existing investment price indices in the U.S. are unlikely to fully 
suggests an alternative, production-side approach to estimating equipment-embodied technological change. ${ }^{5}$ Wilson uses this approach to obtain industry-level estimates of embodied technological change, which can be used to construct quality-adjusted measures of productive capital.

In the current paper, I use the results from Wilson (2001) to analyze the effect on the IDLIFT model of replacing the current labor productivity equations, which contain no influence of investment, with Solow-type equations, estimated using appropriately measured productive capital stocks.

Section 2 of this paper describes the structure, particularly of the labor productivity equations, of the IDLIFT input-output simulation and forecasting model. I also discuss the shortcomings of the current labor productivity equations that motivated the proposed changes suggested in this paper. In Section 3, I briefly discuss the methods by which Wilson (2001) obtains estimates of equipment-embodied technological change and I describe how I construct quality-adjusted $^{6}$ equipment capital stocks using the industry-level estimates of capital-embodied technological change from Wilson (2001). The estimation of several alternative sets of productivity equations utilizing the constructed capital stocks is described in Section 4. In

account for all quality change. Wilson therefore suggests inferring embodied technological change directly from cross-sectional production data.

${ }^{5}$ It should be noted that the production-side approach in Wilson (2001) and the estimation of embodied technological change for aggregate U.S. manufacturing was a collaborative effort with Plutarchos Sakellaris (see Sakellaris and Wilson (2002)). Wilson (2001) extended these empirical results to the industry-level and presented a separate method of deriving rates of embodied technological change for non-manufacturing industries. References to earlier, different production-side approaches to estimating embodied technological change are given in Sakellaris and Wilson (2002).

${ }^{6}$ In the context of the capital, the terms quality and embodied technological change should be thought of as synonymous. 
Section 5, base forecasts are generated for both the current version of the model and the new, rival version. Two alternative scenarios, or "shocks," are then introduced to each model and the deviations from base are compared. Section 6 concludes.

\section{Brief Overview of the IDLIFT model}

\subsection{The structure of IDLIFT}

The IDLIFT model was developed and is maintained by the INFORUM research center at the University of Maryland. Since its founding in 1967 by Clopper Almon, Inforum has been building, and encouraging others to build, regression-based structural macroeconomic models based on input-output relationships between industries. ${ }^{7}$ The Inforum modeling philosophy differs from that of other large-scale macro models primarily in the input-output structure underlying the model.

Inforum's main model of the U.S. economy is IDLIFT, which is presently in the process of replacing its predecessor, LIFT (Long-term Interindustry Forecasting Tool). ${ }^{8}$ In this section, I will discuss the general structure of the IDLIFT model as it currently stands. For a discussion of how IDLIFT differs from the LIFT model and planned future changes to the model (aside from those proposed in this paper), see Meade (1999).

The IDLIFT model forecasts output, employment, prices, exports, imports and

\footnotetext{
${ }^{7}$ Inforum stands for Interindustry Forecasting at the University of Maryland. It is a nonprofit research center, founded by Clopper Almon in 1967, which provides industry-level and macroeconomic forecasting and policy analysis. Douglas Meade has been largely responsible for the development of IDLIFT.

${ }^{8}$ The "ID" in IDLIFT stands for Interdyme, the C++ framework developed at Inforum for building interindustry dynamic macroeconomic models (LIFT was built using Fortran).
} 
interindustry flows for 97 commodity sectors; personal consumption expenditures (PCE) for 92 categories; equipment investment by 55 industries; construction spending for 19 categories; and the components of value-added for 51 industries. In addition, the model provides a full accounting of the macroeconomy. Macroeconomic variables such as the personal savings rate or the 3-month Treasury bill rate are estimated econometrically. Others are determined according to national accounting identities and still others are given to the model exogenously.

The overall structure of the model is based on the national accounting system embodied in the U.S. National Income and Product Accounts (NIPA). The model has a real side and a price side. On the real side, each component of final demand (i.e., the usual $\mathrm{C}+\mathrm{I}+\mathrm{G}+\mathrm{X}-\mathrm{M}$ ) is modeled at the various levels of disaggregation mentioned above using structural behavioral equations. The disaggregate, sectoral equations are estimated individually (as is the case with the labor productivity equations) or as a system (such as a demand system for consumption equations) using mainly industry-level time series data. Bridge matrices convert each of these final demand components from their particular level of disaggregation to the 97-sector commodity level. Sectoral (gross) output is then determined according to the fundamental inputoutput equation:

$$
\mathbf{q}=\mathbf{A q}+\mathbf{f}
$$

where $\mathbf{q}$ is a $97 \times 1$ vector of output, $\mathbf{A}$ is the intermediate coefficient matrix (also called the inputoutput matrix or the requirements matrix), and $\mathbf{f}$ is the vector of final demand:

$$
\begin{aligned}
f_{97 \times 1}= & H_{97 \times 92}^{c} c_{92 \times 1}+H_{97 \times 55}^{e q} e q_{55 \times 1}+H_{97 \times 19}^{s} s_{19 \times 1} \\
& +i_{97 \times 1}+x_{97 \times 1}-m_{97 \times 1}+g_{97 \times 1} .
\end{aligned}
$$

The subscripts indicate the dimension of each matrix or vector. Here $\mathbf{c}$ denotes the consumption 
vector, eq denotes equipment investment by purchaser, $\mathbf{s}$ structures investment (construction) by type of structure, $\mathbf{i}$ inventory change, $\mathbf{x}$ exports, $\mathbf{m}$ imports, and $\mathbf{g}$ government spending. ${ }^{9} \mathbf{H}^{\mathrm{j}}$ is the bridge matrix for component $j$. All of the variables in equations (1) and (2) should rightly have time subscripts as well, including the $\mathbf{A}$ and $\mathbf{H}$ matrices which vary according to trends in the across-the-row totals. A detailed discussion of the equations or systems that forecast the components of the final demand vector is beyond the scope of this paper but is available in Meade (1999).

Given the forecasted vector of output $\left(\mathbf{q}^{*}\right)$, employment (number of jobs) by sector is computed as:

$$
\mathbf{n}^{*}=\mathbf{q}^{*}\left(\frac{\mathbf{1}}{(\mathbf{q} / \mathbf{l})^{*}}\right)\left(\frac{\mathbf{l}}{\mathbf{n}}\right)^{*}
$$

where $\ell$ is hours worked. An asterisk indicates that a variable is forecasted by the model. For instance, $\ell$ is not a variable in the model per se (it is determined by identity once $[\ell / \mathbf{n}]^{*}$ and $\mathbf{n}^{*}$ are forecasted), but the average hours per job ( $(/ \mathbf{n})$ and labor productivity $(\mathbf{q} / \ell)$ are. Employment forecasts $\left(\mathbf{n}^{*}\right)$, together with forecasts of the labor force, determine the unemployment rate, a key variable in the model. Aside from being of obvious interest in its own right, the unemployment rate affects many macroeconomic and industry equations on both the real and the income side of the model. By extension, then, it is evident that labor productivity is a key driver of the model (both through its effect on the model's unemployment rate and through its own direct presence in

${ }^{9}$ In the model, government spending is actually decomposed into 5 components such as state and local spending, defense spending, etc. The macro-level of these components are generally exogenous to the model; the exogenous macro values are shared-out to the 97 sector level using the sectors' shares of that component of government spending from the most recent year of available data. 
many model equations).

On the income/price side of the model, prices at the 97-sector level are determined according to equations modeling the markups over unit intermediate and labor costs. Given this forecasted price vector $\mathbf{p}(97 \times 1)$, value added by commodity sector $(\mathbf{v})$ is calculated as a residual using the dual of the fundamental input-output equation:

$$
\mathbf{p}=\mathbf{p A}+\mathbf{v}
$$

The components of value added (corporate profits, inventory valuation adjustment, capital consumption adjustment, net interest income, rental income, indirect taxes, government subsidies, and the big one: labor compensation) are each modeled separately. The forecasted values of the capital income components (everything except labor compensation) are then scaled to be consistent with equation (4) and the markup forecasts. Hourly labor compensation is modeled as a function of the growth in M2/GNP, the growth in labor productivity, and a supply shock (it is then multiplied by the forecast of the labor hours requirement, $\ell$, from the real side). So labor productivity has an important influence on the income side of the model as well.

\subsection{The Problem and the Need for Change}

With its considerable influence on labor compensation on the income side and employment and the savings rate on the real side, it should be evident by now that labor productivity is one of the most important variables in the IDLIFT model as well as virtually any other large-scale structural macro model. Currently, the IDLIFT model's labor productivity equations are determined essentially by time trends and the difference between industry output and its previous peak, and does not contain any factor inputs as explanatory variables. The form of each 
industry's equation is as follows:

$$
\ln \left(q_{i t} / l_{i t}\right)=\beta_{0}^{i}+\beta_{1}^{i} t_{1}+\beta_{2}^{i} t_{2}+\beta_{3}^{i} q u p_{i t}+\beta_{4}^{i} q d o w n_{i t}
$$

where: $t_{1}=$ a linear time trend starting in the first year of data;

$t_{2}=$ a second time trend, starting in 1972;

$\operatorname{qup}_{t}=d q_{\mathrm{t}}$, when $d q_{t}>0,0$ otherwise;

qdown $n_{t}=-d q_{t}$, when $d q_{t}<0,0$ otherwise;

$d q_{t}=\log \left(q_{t}\right)-\log \left(\right.$ qpeak $\left._{t-1}\right)$

$\operatorname{qpeak}_{t}=q_{t}$, if $q_{t}>\operatorname{qpeak}_{t-1}(1-$ spill $)$, otherwise $=\operatorname{qpeak}_{t-1}(1-$ spill $)$;

spill $=$ depreciation rate of capacity;

and $i$ indexes the 55 industries.

Inforum has long had difficulty building into its models a sensible relationship between investment and labor productivity. Given that labor productivity is the key driver of the long-run output growth behavior of the model, the lack of an influence from investment or capital stock is lamentable. Virtually any Solow-type growth model attributes a substantial share of output growth to the growth of capital. Its omission from Inforum models, IDLIFT in particular, is due neither to a disbelief in Solowian production theory nor to a lack of effort.

Many valiant attempts have been made over the years to develop and estimate productivity equations based on firm optimization behavior that incorporate the effects of changes in capital stock. These attempts have generally been foiled by one of two problems. First, in industry-level time-series regressions (with which the IDLIFT equations are typically estimated), the capital coefficient is often found to be negative and/or near-zero (particularly in service sectors). Second, because the investment equations in IDLIFT have always been of a flexible accelerator- 
type nature (i.e. driven largely by current and lagged changes in output), the introduction of investment (via capital stock) into the productivity equations provided a seed for the explosion of output in the model's forecast. That is, any exogenous positive shock to the model caused output to grow, which caused investment to grow, which caused labor productivity to grow, which caused output to grow (mainly through productivity's increasing of the wage rate which lowers the savings rate which thus spurs consumption, the largest component of final demand),...ad infinitum. The model has lacked a supply constraint (such as a nonconvex adjustment cost in the investment equations) to put the brakes on investment and stabilize output. For these reasons, IDLIFT's labor productivity equations (as well as those of other Inforum-type models) have heretofore remained essentially a series of time trends.

The maintained hypothesis has been that one of the key problems with finding a successful Solow-type equation has been mismeasurement of capital due to unobserved changes in embodied technology. It is well-known that classical measurement error causes an attenuation bias (toward zero) on the coefficient associated with the mismeasured independent variable. In fact, the problem is even worse. The measurement error in equipment capital that is caused by ignoring embodied technological change is not random; it is systematically related to the intertemporal investment distribution. The error will be greater the more an industry's capital is comprised of recent vintages. Recent investment will be positively correlated with other factor inputs such as labor. This will lead to an upward bias in the estimated labor elasticity. Furthermore, if constant returns to scale are imposed, this positive bias in labor elasticity implies a lower capital elasticity (in a value-added production function).

Thus, in order to correct this measurement problem, in the next section I construct qualityadjusted capital stocks. In Section 4, I estimate alternative labor productivity equations which 
attempt to avoid the measurement error by using quality-adjusted capital stocks.

\section{Measuring Quality-Adjusted Capital}

\subsection{Conceptual Framework}

As discussed above, quality-adjusted capital stocks are needed in order to properly estimate labor productivity equations that are of a Solow-type specification. In addition, for a structural model that forecasts labor productivity based partially on forecasted capital, a capital stock formula must be built into the model such that capital can be updated in each future period using the model's forecast of investment. The capital stocks I construct in this paper are defined according to the usual perpetual inventory formula that aggregates current and past vintages of investment into a current real capital stock according to some weighting scheme (i.e., a distributed lag):

$$
k_{t}=\sum_{s=1}^{T} i_{t-s} \cdot[\underbrace{\left[\left(\frac{1}{p_{t-s}}\right) D_{t, t-s}(1+\gamma)^{t-s-t_{0}}\right]}_{\operatorname{Weight}(t-s)}
$$

where $k$ is the capital stock (either equipment or structures), $i$ is nominal investment, $p$ is the price deflator, $\gamma$ is the rate of capital-embodied technological change, and $D_{t, t-s}$ captures physical depreciation (i.e., wear and tear). $D_{t, t-s}$ gives the fraction of vintage $t$-s capital still in production in year t. In most capital stock data constructs, the quality (technological) change component is generally considered to be included in either the measure of depreciation (making it economic 
depreciation rather than physical depreciation) or the price deflator. ${ }^{10}$ Unfortunately, most data sources of investment price deflators and economic depreciation do not adequately adjust for quality change in equipment. Thus, it is important to decompose the vintage weights in equation (6) into the three separate components of physical depreciation, quality change, and price change and properly measure each.

Using the definition of capital in equation (6), I construct separate industry-level capital stocks for structures and equipment. For structures, I assume that technological change is negligible and thus $\gamma=0$. For equipment, the rates of embodied technological change come from Wilson (2001) and are detailed below. As for the price deflator, Hornstein and Krusell (1996) show that if embodied technological change is measured independently, one should deflate investment by a consumption deflator, which I do for both equipment and structures. I measure physical depreciation in structures as the inverse of the weighted average of the service lives of the structures assets owned by the industry. The weights are the asset types' shares of the industry's capital. Data on these shares and the service lives come from the U.S. Bureau of Economic Analysis (BEA).

\subsection{Physical Depreciation of Equipment}

The Board of Governors of the Federal Reserve (FRB) and the U.S. Bureau of Labor Statistics (BLS) construct equipment capital stocks using a methodology for capturing physical depreciation based on stochastic service lives and a nongeometric, "beta-decay" function. In Sakellaris and Wilson (2000), we back out the implied industry-level physical depreciation

\footnotetext{
${ }^{10}$ See Gort and Wall (1998) or Hulten and Wykoff (1981) for discussions of the distinction between economic and physical depreciation.
} 
patterns, $D_{t, t-s}$, for equipment from the FRB capital stocks. However, the fact that the equipment stocks will need to be forecasted introduces a complication into how they must be constructed. The physical depreciation schedules constructed in Sakellaris and Wilson (2000) are functions of both year $(t)$ and age $(s)$. In order to "forecast" physical depreciation for future years, one must make some assumption regarding how $D_{t, t-s}$ will vary over $\mathrm{t}$ in the future. What is needed is a time-invariant physical depreciation pattern to apply to the forecasted investment flows. One would also like this pattern to match as closely as possible the FRB physical depreciation schedules since these schedules were used in Wilson (2001) for estimating $\gamma$ with plant-level data. Thus, I use the average (over years and industries) age profile from those schedules. The average profile is shown in Figure 1 by the line labeled "Actual." It has a reverse-S shape.

To impose the reverse-S-shaped pattern of physical depreciation on historical and forecasted values of investment, what is needed is a function with a minimal number of parameters that can mimic this reverse-S shape. I found such a function in the "cascading buckets" concept from Almon (1998). A cascading buckets system is a combination of several "bucket" functions. A single bucket function is a perpetual inventory capital accumulation function such as the following:

$$
k_{0}=0 ; \quad k_{t}=(1-z) k_{t-1}+i_{t} \quad \forall t>0
$$

The variable $i_{t}$ is the inflow into the bucket, $k_{t}$, while $z k_{t-1}$ is the outflow of the bucket. If the inflow ceased $\left(i_{t}=0\right.$ for future $t$ ), the age profile (physical depreciation schedule) of $k_{t}$ would be a geometric decline.

The reverse-S shape can be obtained by a "cascading" of two or buckets, i.e. by having the outflow of the first bucket (here, $z k_{t-1}$ ) be the inflow into the second bucket, then the outflow of the second bucket be the inflow into a third bucket, and so on.... The final, cascading buckets 
function is the sum of these buckets.

In fact, even more variety of shape can be obtained by letting the inflow into the lower (i.e. second, third, ...) bucket "splatter out" or "miss" some of the lower bucket so that only $(z-\mathcal{E}) k_{t-1}$ actually flows into it (and $\varepsilon k_{t-1}$ is lost). Allowing some "splatter" turns out to be quite necessary for fitting the average physical depreciation schedule in Figure 1 because without the splatter there would be no decrease in efficiency over the first $\mathrm{N}-1$ years, where $\mathrm{N}$ is the number of buckets (i.e. without splatter, nothings falls out of the bucket system until there is no longer a lower bucket to catch the last bucket's outflow). A decrease in efficiency beginning in the first year is a property of the age-efficiency schedule I am trying to fit.

Using the following three-bucket system, I was able to very closely replicate the age profile implied by the average physical depreciation schedule shown in Figure 1:

$$
\begin{aligned}
& k_{1, t}=(1-A) k_{1, t-1}+1_{t} \\
& k_{2, t}=(1-B) k_{2, t-1}+(A-\varepsilon) k_{1, t-1} \\
& k_{3, t}=(1-B) k_{3, t-1}+A k_{2, t-1}
\end{aligned}
$$

where $1_{t}$ is a variable that is one at age zero and zero thereafter. Allowing $\mathcal{E}>0$ results in some of the outflow from $k_{1}$ to splatter out or miss $k_{2}$ allowing for efficiency loss immediately after the first year. I performed a grid search to find the parameters $A, B$, and $\varepsilon$ which resulted in the lowest sum of squared errors (SSE). The values $A=0.14, B=0.3$, and $\varepsilon=0.011$ led to a SSE < 0.001. Figure 1 shows the fitted values from this cascading bucket versus the actual depreciation schedule. Clearly, the fit is extremely close. This three-bucket system with the above parameter values formed the $D_{t, t-s}$ used in the construction of the equipment capital stock, as defined in equation (6). Now, rather than $l_{t}$ going into the first bucket, the actual equipment investment 
(adjusted for embodied technological change) flows in:

$$
\begin{aligned}
& k_{1, t}=(1-0.14) k_{1, t-1}+i_{t}(1+\gamma)^{t-t_{0}} \\
& k_{2, t}=(1-0.3) k_{2, t-1}+0.129 k_{1, t-1} \\
& k_{3, t}=(1-0.3) k_{3, t-1}+0.14 k_{2, t-1} \\
& j_{t}=k_{1, t}+k_{2, t}+k_{3, t}
\end{aligned}
$$

where $i_{t}(1+\gamma)^{t-t_{0}}$ is vintage equipment investment adjusted for embodied technological change assumed to take place at the rate $\gamma$, and $j$ is the resulting quality-adjusted equipment capital stock.

\subsection{Wilson (2001)'s method of quantifying embodied technological change}

The production-side method developed in Wilson (2001) estimates embodied technological change $(\gamma)$ for U.S. manufacturing industries directly from observed production, input, and investment decisions at the plant level using the Longitudinal Research Database of the U.S. Census Bureau. Specifically, Wilson estimates a gross-output production function in which the equipment capital input is as defined in equation (6). The parameter $\gamma$ is estimated via non-linear least squares along with the usual production function factor elasticity parameters.

The empirical results are shown in the top panel of Table 1. The estimates of embodied technological change generally are clustered around 5-10\%. 15 of the 24 industries had positive estimates with 9 being significant. Of the 9 negative estimates, 5 were significant. These estimates seem quite reasonable in their ordering, but the presence of negative estimates (which are at best counter-intuitive and at worst nonsensical) and unrealistically high estimates for producers of Computers and Communications Equipment as well as the relative imprecision of the estimates leaves some skepticism regarding the usefulness of these estimates. 
Evaluating the reasonableness of the estimated rates of embodied technological change and deriving analogous rates for nonmanufacturing industries, for which longitudinal plant-level data is not currently available, was the motivation for Wilson (2002). In that study, Wilson constructs an index capturing the extent of research and development directed at the various capital goods that constitute a given industry's capital stock. Specifically, he combines (and adjusts) data from the National Science Foundation and the Commerce Department to construct a weighted average of the $R \& D$ done on the equipment capital that an industry purchases (for 62 industries that span the U.S. private economy). This industry-level index of capital-embodied R\&D is shown to have a large, positive correlation with the manufacturing estimates of embodied technological change.

The estimated relationship in manufacturing between embodied technological change and the index of embodied R\&D, along with the index values for nonmanufacturing industries, is used to impute nonmanufacturing rates of embodied technological change. These rates are shown in the bottom panel of Table 1 . They range from 0 to $11 \%$. It should be noted that the estimated coefficients in the imputation regression have large standard errors, thus the imputed rates have correspondingly large standard errors associated with them. Nonetheless, the magnitudes and the cross-sectoral ranking of these rates of embodied technological change are quite reasonable. For instance, the lowest imputed rates of embodied technological change are found in mining industries which, not surprisingly, invest mainly in mining equipment which has historically experienced very little R\&D. The highest rate is in Communications Services which invests mainly in R\&D-intensive equipment such as telecommunication equipment and computers. 


\section{Alternative Labor Productivity Equations}

In this section, I describe a general-to-specific modeling exercise involving several alternative specifications for labor productivity equations. I began with a number of specifications that are nested in a more general model and then evaluated their performance in terms of average fit (over all industries) and the signs and magnitudes of the coefficient estimates. Based on this evaluation, the set of specifications is pared down to a smaller set of candidate specifications. Finally, a single specification is chosen for each industry based on fit and the sensibility of the coefficients obtained from each modification.

This approach of estimating a number of specific equations that are special cases of a more general model and choosing a single equation for forecasting based on economic and statistical criteria, is similar to the general-to-specific modeling approach recommended by Hendry $(2000){ }^{11}$

\subsection{The general model and the specifications nested within it}

In this subsection, I describe the results of estimating 9 alternative specifications for a labor productivity equation. Each specification is estimated for each of the 55 industries in the IDLIFT investment sectoring scheme. ${ }^{12}$ Table 2 shows the functional forms of the 9 specifications and provides a guide to how they differ from one another. With the exception of the current IDLIFT specification, all of the specifications are derived from a standard Cobb-Douglas Solow-type production function:

${ }^{11}$ General-to-specific modeling is also known as the LSE methodology.

${ }^{12}$ Actually industry 55 (Scrap and used equipment) was omitted due to lack of data. 


$$
q_{i t}=\ell_{i t}^{\beta} j_{i t}^{\alpha} s_{i t}^{\eta}
$$

where $q$ is real gross output, $\ell$ is labor hours, $j$ is equipment capital services, $s$ is structures capital services, and $i$ indexes industries. Capital services, for either equipment or structures, are the flow of services derived from the real, constant-quality, capital stock in place. Thus, ideally capital services should reflect the utilized capital stock. ${ }^{13}$

The first specification (labeled A) is simply the standard Cobb-Douglas production function in logs, rearranged so as to have log output per hour $(\log (q / \ell))$ on the left-hand side. This specification assumes that the rate at which each type of capital is utilized is constant (and thus the utilization rate only affects the constant term of the regression).

The next specification (B), on the other hand, allows for non-constant utilization of capital and proxies for the utilization rate using the energy-capital ratio following Sakellaris and Wilson (2000). Specifically, the utilization rate of capital (either equipment or structures) is assumed to be an increasing (and isoelastic) function of the ratio of energy expenditures (fuel and electricity) to the capital stock: $U^{J}=(e / j)^{1 / \tau}$ and $U^{S}=(e / s)^{1 / \tau}$. The parameter $\tau$ is the elasticity of energy intensity with respect to capital utilization; i.e., to increase utilization by $1 \%$, one must increase the energy-capital ratio by $\tau \%$. The special case $\tau=\infty$ means that there is no variation in utilization; $\tau=1$ means energy use is perfectly proportional to capital services; and $\tau=0$ means an infinitesimal change in the energy-capital ratio will fully adjust utilization to the desired level. Multiplying the expressions for $\mathrm{U}^{\mathrm{J}}$ and $\mathrm{U}^{\mathrm{S}}$ by $j$ and $s$, respectively, in equation (7) and then

\footnotetext{
${ }^{13}$ The construction of the equipment and structures stocks are described in Section 3.
} 
rearranging (and taking logs) yields specification (B) shown in Table 2. The specification can be estimated via OLS and the parameters $\tau, \beta, \alpha$, and $\eta$ can be solved for from the estimated coefficients.

The third specification $(\mathrm{C})$ begins with the standard Cobb-Douglas form but imposes constant returns to scale (RTS). The fourth specification (D) combines constant RTS with the adjustment for capacity utilization. The fifth specification (E) is the current IDLIFT labor productivity equation, equation (5) above. The next four specifications (F, G, H, I) are exactly the same as the first four except the equipment capital stock is not adjusted for embodied technological change, i.e., $j$ is constructed with $\gamma$ set equal to zero. ${ }^{14}$

It should be noted here that all of the above specifications omit materials (intermediate inputs) as an input into the gross output production function. This omission is done for a number of reasons. First, it is often the case in production or productivity regressions that intermediate inputs dominate the explanatory power of the independent variables and obscure the effects of the other inputs. ${ }^{15}$ A second problem with including materials in industry-level production function regressions is that data on materials is often inadequately measured. Real materials for an industry is defined as the sum of the industry's column in the constant-dollar intermediate (input-output) flows matrix. That is, real materials for industry $j$ is $m_{j t}=\sum_{i} a_{i j t} q_{j t}$ where $a_{i j t}$

\footnotetext{
${ }^{14}$ For the structures stock, $\gamma$ has been set equal to zero for all nine equations.
}

${ }^{15}$ This domination by materials appears to be the case in our regressions as well. When materials are included in the 9 specifications above and they are then estimated via OLS over each of the 55 industries, the regressions yield very high coefficient estimates and enormous mexval statistics (marginal explanatory power) corresponding to the output elasticity with respect to materials. Furthermore, all but specification E (the current IDLIFT equation, which does not include materials) have very high adjusted- $\mathrm{R}^{2}$ 's. 
is element $(i, j)$ in the intermediate coefficient matrix ( $\mathbf{A}$ in equation (1)). The problem is that we do not observe the true input-output coefficients, $a_{i j t}$, in most years (at least in the U.S. data). Specifically, we only have data on $a_{i j t}$ on a quinquennial basis as the BEA only constructs an input-output table every 5 years. Coefficients for years in between are simply interpolated between benchmark-year coefficients and are therefore essentially determined by $q_{j t}$. Thus, shocks in $q_{j t}$, which affect the dependent variable in a productivity regression and are part of the regression disturbance term, are transmitted to the regressor $\log \left(m_{j t} / \ell_{j t}\right)$ causing an upward bias in the estimator of its coefficient. ${ }^{16,17}$

\subsection{Average results - narrowing list of candidate specifications}

Each of the 9 specifications described above (and in Table 2) was estimated individually via OLS for each of the 55 industries in IDLIFT (spanning the U.S. private economy). The data come from various U.S. government sources and were compiled by Inforum. The results are summarized in Table 3. The first column of the table identifies the specification, the second column gives the average (over the 55 industries) adjusted- $\mathrm{R}^{2}$, the third through the seventh column give the average coefficient estimate for each production function parameter, and the eighth through the twelfth column give, for each parameter, the percentage of industries for which the coefficient estimate is positive.

\footnotetext{
${ }^{16}$ In fact, exactly the same problem is true for our measures of real energy expenditures which are also constructed via slow-moving input-output coefficients multiplied by industry output.

${ }^{17}$ The omission of materials can be justified theoretically by assuming the Leontief conditions for separability of materials and value added, as is frequently done in the production literature (e.g., Basu (1996) and Wilson (2000)). That is, $Y=\min [M, F(J, S, L)]$. Assuming firms are optimizing, this implies $\operatorname{dlog}(Y)=\operatorname{dlog}(F(J, S, L))$.
} 
In assessing the average coefficient estimates, one should keep in mind the generally accepted a priori values for the elasticities of output with respect to each of the factor inputs. Based on the shares of national income going to labor and capital, one would expect the elasticities of labor and capital to be $2 / 3$ and $1 / 3$, respectively. The capital share is further broken down generally to be $2 / 3$ 's equipment and $1 / 3$ structures. Thus, one would expect our estimates of the output elasticities with respect to each input to be somewhat close to these values. That is, one would expect $\alpha=(1 / 3)^{*}(2 / 3)=2 / 9 \approx 0.22, \eta=(1 / 3)^{*}(1 / 3)=1 / 9 \approx 0.11, \beta=0.66$.

Several important conclusions can be drawn from Table 3. First, all of the specifications that are based on the Cobb-Douglas production function have similar average fits to the current IDLIFT specification (E), which is notable given that a high goodness-of-fit was the main motivation for using specification E in the IDLIFT model in the past. Second, I find for the most part that adjusting equipment capital for quality using the $\gamma$ s from Table 1 substantially improves the fit and sensibility (in terms of average value of estimated factor elasticities) of the labor productivity equations in comparison to using an unadjusted equipment capital stock (compare A to F, B to G, C to H, and D to I). Third, despite some loss of fit, imposing constant RTS seems to improve the sensibility and positivity of the estimates (compare C to A, D to B, H to F, and I to G). The beneficial effects that imposing constant RTS has on $\alpha$ and $\eta$, in terms of increasing the percentage that are positive and raising their average values closer to $a$ priori expectations based on income shares, seems to outweigh the cost of a slightly lowered fit. Lastly, controlling for utilization using the energy-capital ratio yields higher average adjusted- $\mathrm{R}^{2} \mathrm{~s}$ but causes excessively high elasticities of structures. It also yields fewer positive estimates of the equipment elasticity. In sum, specifications that (1) adjust for embodied technological change in the measure of equipment capital, (2) impose constant returns to scale, and (3) do not use energy- 
capital ratios as a proxy for unobserved capital utilization appear to outperform their alternative specifications. Only specification (C) satisfies all three of these criteria.

Though adjusting for utilization using the energy-capital ratio did not lead to an improvement in results, there is one other approach to measuring utilization that should probably be tried before abandoning the theoretically attractive notion of accounting for variations in capacity utilization. This approach is that used in the current IDLIFT equation. Variation in utilization is captured by including the terms qup and qdown as defined in equation (5). The method first measures capacity with the previous peak level of industry output less some "depreciation." The absolute value of the percentage difference between current output and capacity is a measure of the output gap and it is included as an additional regressor, with positive and negative differences treated asymmetrically. The rationale for this method is that when current output is being stretched beyond the previous peak level, the economy will be pushing up against capacity constraints, and when output is much below the previous peak, there is excess capacity not being utilized.

To evaluate the efficacy of this method, I estimate an equation identical to $\mathrm{C}$ but with qup and qdown as additional independent variables. Call this specification $\mathrm{C}_{+\mathrm{gap}}$. The results of estimating this specification for each industry are shown near the bottom of Table 3. Compared to using the energy-capital ratio as a proxy for utilization (specification $\mathrm{D}$ ), specification $\mathrm{C}_{+\mathrm{gap}}$ yields slightly lower fits but far more reasonable capital elasticities. Compared to results for specification $\mathrm{C}$, the specification that does not account for variation in utilization, those for specification $\mathrm{C}_{+ \text {gap }}$ are quite similar in both fit and capital elasticities. This makes specification $\mathrm{C}_{+\mathrm{gap}}$ a rather attractive option relative to $\mathrm{C}$ given the theoretical appeal of accounting for variation in capital utilization. 


\subsection{Checking for simultaneity bias}

One concern, however, with specification $\mathrm{C}_{+\mathrm{gap}}$ is the possibility of reverse causation (a.k.a. simultaneity bias) since industry-level output is part of both the dependent variable and the regressors qup and qdown. If there is any measurement error in output, this may bias the coefficients on qup and qdown as well as artificially inflate the $\mathrm{R}^{2}$ 's. The bias can be seen formally by assuming that there is an i.i.d. measurement error in q: $q^{\text {measured }}=q^{\text {true }}+v$, where $v \sim$ $\mathrm{N}\left(0, \sigma^{2}\right)$. So our regression equation $\left(\mathrm{C}_{+ \text {gap }}\right)$ becomes:

$$
\begin{aligned}
\log \left(q^{\text {measured }} / \ell\right)_{t} & =c_{0}+c_{0} t+\alpha \log (j / \ell)_{t}+\eta \log (s / \ell)_{t} \\
& +a_{3} q u p_{t}^{\text {measured }}+a_{4} q d o w n_{t}^{\text {measured }}+u_{t}
\end{aligned}
$$

Notice that $v$ will be contained in the dependent variable as well as qup and qdown resulting in spurious correlation between these two regressors and the dependent variable. The bias on the estimator of $a_{3}$ will be positive and that of $a_{4}$ will be negative.

To evaluate the seriousness of this problem, I perform a mixed empirical-Monte Carlo estimation procedure. In this procedure, I specify the data generating process (DGP) for the true dependent variable as:

$$
\begin{aligned}
\log (q / \ell)_{t}^{\text {true }} & =2+0.01 t+0.17 \log (j / \ell)_{t}+0.16 \log (s / \ell)_{t} \\
& +0.1 q u p_{t}^{\text {true }}-0.1 q d o w n_{t}^{\text {true }}+\varepsilon_{t}
\end{aligned}
$$

where $\epsilon_{t} \sim \mathrm{N}\left(0,4 \times 10^{-06}\right)$; the variance of $4 \times 10^{-06}$ implies the standard deviation of the i.i.d. shock to true productivity is 0.002 . The 0.1 and -0.1 assumed coefficients represent the true relationship between qup and qdown and labor productivity, i.e. absent any spurious correlation due to the presence of measurement error in $q$. I further assume that $\sigma$, the standard deviation of 
the measurement error in log output is 0.05 . Using the DGP specified in equation (9), I construct the "true" dependent variable, and then I regress it on $t, \log (j / \ell), \log (s / \ell)$, qup ${ }^{\text {measured }}$, and qdown ${ }^{\text {measured }}$ each measured with actual historical time series. I repeat this procedure 2000 times and calculate the mean and standard deviation for each coefficient. ${ }^{18}$

The coefficient means and standard deviations are shown in Table 4. The estimated biases are all extremely close to zero. Thus, even assuming a very large variance for the measurement error in $q$, coefficient bias due to the presence of qup and qdown does not appear to be a problem.

\subsection{Checking for spurious correlation due to omitting time trends}

At this point, it appears that specifications $\mathrm{C}$ and $\mathrm{C}_{+\mathrm{gap}}$ are promising alternative options to the current IDLIFT equation (specification E). However, it is possible that there is some spurious positive correlations between labor productivity and the factor inputs due to the fact that these variables are all trended upward. In other words, the above equations should probably also contain a Hicks-neutral productivity (or disembodied technology) term that is sure to be highly trended. Hence, adding a time trend to these equations will greatly mitigate any spurious relationship between labor productivity and the factor inputs.

The results of estimating equations $\mathrm{C}$ and $\mathrm{C}_{+ \text {gap }}$ with single linear time trends added, labeled $\mathrm{C}_{+\mathrm{t}}$ and $\mathrm{C}_{+\mathrm{gap},+\mathrm{t}}$, respectively, are shown at the bottom of Table 3 . The adjusted $\mathrm{R}^{2}$ 's for both of these specifications are now slightly better than that of the current IDLIFT equation

${ }^{18}$ I arbitrarily choose the "Printing and Publishing" industry for the historical data. The choice of industry should not affect the coefficient means (and therefore their biases) but may affect the standard deviations since the sample variance of a variable helps determine the variance of its coefficient (and, of course, the sample variance of a variable will be different across industries). To be sure, I repeated the procedure with a $2^{\text {nd }}$ industry and obtained similar estimated biases. 
(specification $\mathrm{E}$ ) at $0.866,0.867$ and 0.843 for specifications $\mathrm{C}_{+\mathrm{t}}, \mathrm{C}_{+\mathrm{gap}, \mathrm{t}}$, and $\mathrm{E}$, respectively. While the average estimated elasticity of structures $(\eta)$ does not noticeably change, the average elasticity of equipment $(\alpha)$ falls considerably below the a priori expected level of 0.22 (thus pushing up the elasticity of labor since there is constant returns to scale).

Thus, specifications $\mathrm{C}$ and $\mathrm{C}_{+ \text {gap }}$ do seem to suffer from spurious correlation between equipment capital and labor productivity due to fact that both of these variables are highly trended. Accounting for this by including a time trend improves the fit of the equations but causes unrealistically low equipment elasticities for many industries. A solution to this dilemma is to use a Bayesian approach that balances improved goodness-of-fit against improved factor elasticities. This would allow us to include time trends in specifications $\mathrm{C}_{+\mathrm{t}}$ and $\mathrm{C}_{+\mathrm{gap}, \mathrm{t}}$ while forcing the factor elasticities, particularly the equipment elasticity, to be closer to a priori expectations. This solution seems far preferable to simply continuing to use the current labor productivity equation in IDLIFT given that these new specifications have at least as good a fit as the current IDLIFT equation and obviously far more economic appeal. Most importantly, they capture the productivity gains due to capital deepening (which, given how capital was constructed here, includes embodied technological change). Therefore, in choosing a single productivity equation for each industry, I attempt to obtain an estimated equation, using a Bayesian technique described below, that fits the data as well or better than the current IDLIFT equation while having reasonable coefficients.

\subsection{Choosing Industry-Specific Labor Productivity Equations}

Above I evaluated many possible specifications for a general empirical model of labor productivity based on the criteria of average fit and the economic realism of the coefficients. The 
results of that evaluation have enabled us to now focus our attention on a narrow candidate list of specifications in determining the "best" one for each particular industry (rather than simply the best on average). Obviously, the specification that yields the best results on average may not necessarily yield the best results for a particular industry. The choice of specification must be made on an industry-by-industry basis.

For each industry, I compare the results of estimating specifications $\mathrm{C}_{+\mathrm{t}}, \mathrm{C}_{+\mathrm{gap},+\mathrm{t}}$, and $\mathrm{E}$. Not surprisingly given the average results, specifications $\mathrm{C}_{+\mathrm{t}}$ and $\mathrm{C}_{+\mathrm{gap}, \mathrm{t}}$ yielded one or more unrealistic coefficients for many industries. For these industries it was necessary to use a Bayesian regression technique known as "softly constraining" in order to force the coefficient estimates to lie inside a realistic range. "Soft constraining," also known as "Theil's mixed estimation" or "stochastic constraints," allows one to combine a priori theoretical beliefs on parameter values with the values estimated using the data. A soft constraint essentially adds artificial observations (or a fraction of an observation) in which the constraint holds exactly. For instance, if one wanted to push the estimate of $\alpha$ in equation $\mathrm{C}_{+\mathrm{t}}$ towards the a priori expected value of 0.22 , one could add the artificial observation $\left\{q_{i t}=0.22, t=0, \log (j / \ell)=1, \log (s / \ell)=0\right\}$ a chosen of times and then estimate the equation via OLS using both the actual and artificial observations. Since a value of 0.22 for $\alpha$ would result in a zero residual for each of the artificial observations, the least squares procedure will look for an $\alpha$ closer to 0.22 than it would have had the artificial observations been excluded. Of course, as $\alpha$ moves away from the least squares value based only on the actual observations, the goodness-of-fit (based on actual observations) of the regression declines. The a priori expectations for the parameter values and the number of artificial observations to add are chosen by the econometrician to balance the improvement in coefficient estimates with the deterioration in fit. 
I only imposed soft constraints if the unconstrained estimated coefficient was outside the range of $[0,0.4]$ for either capital elasticity $(\alpha$ and $\eta),[0,1]$ for the coefficient on qup, and $[0,-1]$ for the coefficient on qdown. The theoretically-based, a priori expected parameter values that I used as soft constraints, when necessary, were 0.22 for the elasticity of output with respect to the equipment stock, 0.11 for the structures elasticity, 0.5 for the coefficient on qup, and -0.5 for the coefficient on qdown. ${ }^{19}$

For a small number of industries, it was clear that the lagged values of the equipment and structures stocks had more explanatory power (with reasonable coefficients) than the current values and, thus, the lagged stocks were used instead. The improved explanatory power afforded by using lagged stocks can be explained by the industry having a time-to-build requirement greater than one year and/or by the presence of substantial learning-by-doing effects.

Table 5 shows the number of industries for which each of the four specifications was chosen (second column) as well as the number, within each specification, that required soft constraining (third column). Recall that the regressors in specification $\mathrm{C}_{+\mathrm{t}}$ are a constant, a time trend, the $\log$ of the equipment-labor ratio, and the $\log$ of the structures-labor ratio. Specification $\mathrm{C}_{+\mathrm{gap}, \mathrm{t}}$ includes these same regressors in addition to qup and qdown. Specification E is the traditional (current) IDLIFT labor productivity equation. Let the specification which is equivalent to specification $\mathrm{C}_{+\mathrm{t}}$ but with lagged capital stocks be denoted specification $\mathrm{X}$.

Specification $\mathrm{C}_{+\mathrm{gap}, \mathrm{t}}$ was chosen in exactly one half of the industries. Specifications $\mathrm{C}_{+\mathrm{t}}$ and $\mathrm{X}$ were chosen for 23 industries collectively. For only 4 industries was labor productivity substantially better estimated by the current IDLIFT equation (E). Overall, all but five industries

\footnotetext{
${ }^{19}$ The rationale behind these a priori values for capital elasticities is explained in subsection 4.2 above. The a priori values for the coefficients on qup and qdown were chosen simply to be at the halfway point of their respective plausible ranges.
} 
required some type of soft constraint(s). In nearly all cases, the soft constraints were quite weak, amounting to only a fraction of an artificial observation. Thus, the equation fits suffered very little due to the use of soft constraints.

\section{Simulation Results}

The estimated equation chosen for each industry was incorporated into IDLIFT through a series of new computer routines which take forecasted values of equipment investment, structures investment, and output and generate values for productivity, hours, and employment, which then get fed back into the model. With these new, alternative routines incorporated into the model (along with the estimates for the productivity equations), one can produce a base forecast that is stable, i.e. a forecast that does not cause any variable to spiral out of control.

In addition, these new routines were programmed into the model in such a way as to allow the model to calculate productivity, hours, and employment using both the new set of equations and the old set of equations. The model user can specify which set of equations he or she would like to feed back into the model. That is, the user can have the model calculate productivity and hours using the new equations but have those calculated values in no way affect the rest of the model, and the same for the old equations. This allows one to generate a base forecast for both the old model (i.e. the model set to have the current IDLIFT equations' forecasts feed back into the model) and the new model (having the new equations feed back into the model). ${ }^{20}$

Since what we are interested in is how the behavior of the two models differs in response to

\footnotetext{
${ }^{20}$ The model using the new, alternative productivity equations will be referred to as the "new" model in this section while the old/current/pre-existing IDLIFT model will be referred to as the "old" model.
} 
changes in economic activity, such as variations in equipment investment, comparing the two base forecasts to one another is of little interest. What will be of interest to us in this section is comparing and contrasting the responses of each model to some exogenous shock to the system. The behavior of each model in response to such an experiment is the only way to illuminate the effect of changing IDLIFT's productivity equations. Since the key difference between the two models is the presence of a direct influence of capital stock on productivity in the new model, the interesting shocks to investigate naturally involve investment.

Moreover, given IDLIFT's dependence on many exogenous, user-supplied assumptions ("fixes"), one cannot fairly compare a forecast from the old model with one from the new model. The existing fixes, which either override or modify the endogenous forecasts produced by the model's equations, were specified in such a way as to produce the most sensible forecast using the current model. Alternatively, these fixes could be specified so as to optimize the sensibility of the new model. However, having each model have its own optimal fixes would confuse the differences in the models' results due to different productivity equations with those due to different sets of fixes. Yet, many of these fixes must be given values for the model to run at all, therefore turning off all fixes is not an option either. Thus, I run both models using the fixes in place for the most recent semi-annual Inforum forecast using IDLIFT (see Inforum (2001)). One important exception is the exclusion of all fixes on industry-level productivity, industry-level employment, and the aggregate unemployment rate. Thus, again, comparison of the two models must be between the models' differences from their own base forecast to a simulation forecast in which a shock was imposed, and not between the models' base forecasts.

To produce base forecasts, I ran each model out to 2015. 1997 was the last year of historical data for most of the industry-level variables in the model, yet much of the aggregate data is 
available through 2000 (or at least through 1998 or 1999) and this data is imposed on the model through fixes (with the exception of the unemployment rate as mentioned above). ${ }^{21}$ The new functions generally result in lower labor productivity and thus higher hours and employment in the base forecast. This result is true even if the output of these functions is not fed back into the model, but it is stronger when feedback does occur. However, this difference in productivity between the base forecasts is largely due to fixes that act to boost productivity in the current model and thus is not very revealing.

\subsection{Response to a Permanent Investment Shock}

For each model, I evaluate the response of the model to a shock in equipment investment. Specifically, with a set of fixes on equipment investment, I override the models' forecasted vectors of equipment investment with the investment vector from the base forecast plus $2 \%$. That is, for each industry I multiply the equipment investment values from the base forecast by 1.02 and force the model to use these new values in all of the functions that make use of equipment investment. Because aggregate equipment investment is known (from NIPA data) through 2000, I impose this fix just for the years beyond 2000.

Figures 2 through 8 plot, for each model, the deviations over the forecast period of key macro variables relative to each model's base forecast. In both models, real GDP rises by about a quarter of a percent relative to the base in the first year in which the $2 \%$ higher equipment investment is imposed. From then on the models diverge substantially. The old model falls to near the base level in the second year, oscillates between $0.05 \%$ and $0.2 \%$ over base through

\footnotetext{
${ }^{21}$ For instance, NIPA data is available on aggregate equipment investment and residential and nonresidential structures through 2000.
} 
2008, then seems to settle at about $0.08 \%$ over base. The new model also comes back down closer to base in 2002 but then rises relative to base almost monotonically until the end of the forecast where it stands at $0.31 \%$ over base. This Solowian response of real GDP, i.e. higher and less variable, to permanently higher equipment investment is what one would have expected and hoped for from the new model.

The increase in labor productivity induced by higher investment also reduces unit labor costs and this reduction lowers the GDP deflator. The GDP deflator rises in the old model in response to the demand stimulus of higher investment. Because of this, the deviation from base in nominal GDP is actually higher in the old model. The different responses of the price level also has an effect on the Treasury bill rate (not shown): the deviation from base is generally lower and less volatile in the new model. The lower interest rates in the new model cause, in part, a smaller deviation in the savings rate.

In both models, the unemployment rate goes down relative to base due to the substantial demand stimulus caused by the increase in investment. However, the deviation is smaller on average in the new model because its increase in labor productivity has an immediate negative effect on employment. This "Ricardian" effect of labor productivity having a short-run negative relationship with employment would have occurred in the old model as well had labor productivity increased substantially, which it did not. ${ }^{22}$ This difference in labor productivity deviations can be seen in Figure 8. Labor productivity in the new model grows steadily to almost $0.4 \%$ above its base level by the end of the forecast. This is compared to the old model in which

\footnotetext{
${ }^{22}$ In Ricardo's later works, he developed the notion that the introduction of machinery can, under certain circumstances such as the sudden introduction of a new type of machinery, have an adverse effect on employment in the short-run. For empirical evidence of this negative short-run effect on employment from a labor productivity shock, followed by a positive long-run effect, see Gali (1999) and Basu, Fernald, and Kimball (1998).
} 
productivity oscillates until it converges to about $0.04 \%$ over base. In short, in the new model, the long-run effect of investment on productivity is ten times what it was in the old model. Furthermore, an inspection of the industry detail of the forecasts reveals that the largest deviations in productivity can be found in industries which have the largest elasticities of equipment capital. The correlation between this elasticity and the deviation in labor productivity is approximately zero in 2001 but rises to 0.96 by 2015 .

\subsection{Response to a Temporary Investment Shock}

Next I impose a one-time shock on each model of $10 \%$ higher equipment investment (relative to that which is forecast by the model's equations) in 2001. Determination of equipment investment returns to each model's investment equations from 2002 on. The shock is assumed to take place in every industry. Figures 9 through 16 show the deviations relative to the base for the same macro variables as in the earlier figures as well as for quality-adjusted equipment capital (Figure 16). ${ }^{23}$ Both models have an initial response of between 1.2 and 1.3 percent in real GDP. After oscillating for several years, the old model returns nearly to its base level. The new model, however, quickly reaches a steady state at approximately three-tenths of a percent above its base. As with the previous experiment, the GDP deflator's deviation is lower in the new model than in the old model, as one would hope for. The GDP deflator converges to the base level over time in the old model whereas it falls steadily relative to the base in the new model. Interest rates deviations move similarly in the two models though they are somewhat less volatile in the new model. The same is true for their savings and unemployment rates. In both

${ }^{23}$ Note that though quality-adjusted equipment capital is shown for both models in Figure 16 , it only has an effect on the other variables (as well as its own future values through the investment equations) in the new model. 
models, unemployment initially drops dramatically in response to the shock, then jumps dramatically, and finally begins to converge to its base level around 2005. The new model has less of a drop and subsequent jump because the positive demand stimulus of raising investment is partially offset by the negative effect on employment that the increase in productivity has in the short-run (the Ricardian effect), though this is dominated by the stimulus as can be seen in Figure 14.

As expected, labor productivity in the old model, after oscillating for several periods, returns to its base level by 2010 and stays there whereas productivity in the new model, after also oscillating for a few years, is permanently above its base level. This permanent increase in productivity in response to a temporary increase in investment is the key difference in the behavior of the two models. In the old model, a one-time jump in aggregate investment only affects labor productivity by directly increasing every industry's final demand, which directly increases their output, which increases their qup which increases their labor productivity. The next year, when equipment investment comes back down, output will likely be below its previous peak making qdown go up which will lower labor productivity. This cycle will fade away over time returning labor productivity to its base level.

In the new model, on the other hand, labor productivity in every industry jumps initially because of both the jump in qup (for the half of all industries that contain qup and qdown in their productivity equation) and the jump in the equipment stock. In the following year, productivity comes back down due to the jump in qdown in the following period but this decline is offset somewhat by the still-present higher level of equipment stock.

There is also a strong and long-lasting positive effect on equipment investment itself from the initial shock. This effect has two causes. First, the 2001 jump in investment causes the 
following year's desired capital stock (constructed and used in the model's investment equations) to rise which increases the forecast of investment for that year which then increases desired capital and investment for the next year, and so on. Second, the increase in final demand in 2001 raises the 2000-2001 change in output. Distributed lags in the change in output are part of the model's investment equations. Thus, the increased change in output in 2001 directly increases investment for the following four years (there are four lags of output change in the investment equations).

The continuing (though depreciating over time) presence of that extra $10 \%$ of equipment purchased in 2001, combined with the long-lasting increase in equipment investment due to the positive feedback from the initial demand stimulus, keeps the quality-adjusted equipment stock about 2\% above its base level from 2005 through the end of the forecast (see Figure 16). The physical depreciation and obsolescence of the extra $10 \%$ of vintage-2001 equipment begins to dominate any positive feedback remaining from the initial stimulus by 2009 and a very slow decline in the equipment stock begins. Shortly thereafter, labor productivity thus begins to decline very slowly. As was the case with the permanent shock, the largest deviations in productivity occur in the industries with large elasticities of equipment stock. The correlation between the estimated elasticity and the deviation in productivity is -0.07 in 2001 but rises to 0.82 by 2015 .

\section{Conclusion}

The preceding experiments show that the introduction of the new labor productivity equations into IDLIFT do have substantial effects on the general equilibrium behavior of the model. With the new equations operating, the macroeconomic variables of the model exhibit 
behavior in response to changes in investment that is more in line with that predicted by the Solow growth model. Importantly, we do not see the model spiral out of control in terms of output or prices when the new equations are introduced as was feared due to the lack of a supply constraint in the investment equations. In general, the macroeconomic situation of the economy is permanently and substantially improved by an increase in equipment investment, even if it is only a one-time shock, according to the new model. In contrast, the macroeconomy of the IDLIFT model without the new equations exhibits a smaller long-run benefit due to a permanent investment increase and little or no long-run benefit from a temporary increase. The permanent and reasonable response of the new model to increases in investment is one of the main contributions of this paper.

This Solowian response in the new model was accomplished through the use of new labor productivity equations that account for both traditional capital deepening (more physical units of capital per worker) and embodied technological change (higher quality units per worker). It is important to note, however, that these new equations were not simply chosen ad hoc and forced into the model but rather chosen based on the economic sensibility of their coefficient estimates and their ability to fit the historical data. It was shown that these economically sensible equations can, in general, fit the historical data at least as well as the economically unappealing, preexisting IDLIFT equations. 


\section{References}

Almon, C. (1998) The Craft of Economic Modeling (College Park, MD, Interindustry Economic Research Fund, Inc.).

Almon, C. (1969) New Developments in Input-Output, Paper presented at the ASSA Meeting, (New York, NY).

Basu, S. (1996) Procyclical Productivity: Increasing Returns or Cyclical Utilization, Quarterly Journal of Economics, 111, pp. 719-751.

Basu, S., Fernald, J. \& Kimball, M. (1998) Are technology improvements contractionary?, International Finance Discussion Paper 625 (Washington, D.C., Federal Reserve Board).

Galí, J. (1999) Technology, Employment, and the Business Cycle: Do Technology Shocks Explain Aggregate Fluctuations?, American Economic Review, 89, pp. 249-271.

Gort, M. \& Wall, R. (1998) Obsolescence, Input Augmentation, and Growth Accounting, European Economic Review, 42, pp. 1653-1665.

Greenwood, J., Hercowitz, Z. \& Krusell, P. (1997) Long-Run Implications of InvestmentSpecific Technological Change, American Economic Review, 87, pp. 342-362.

Hendry, D. F. (2000) Econometrics: Alchemy or Science? (Oxford, Oxford University Press).

Hornstein, A. \& Krusell, P. (1996) Can Technology Improvements Cause Productivity Slowdowns?, in: J. J. Rotemberg \& B. S. Bernanke (eds) NBER Macroeconomics Annual 1996 (Cambridge, MA, MIT Press).

Hulten, C. R. \& Wykoff, F. C. (1981) The Measurement of Economic Depreciation, in: C. R. Hulten (eds) Depreciation, Inflation, and the Taxation of Income From Capital (Washington, D.C., Urban Institute).

INFORUM (2001) Inforum Forecast Spring 2001 (College Park, MD, IERF, Inc.).

Meade, D. S. (1999) IDLIFT - Recasting the Inforum Model of the U.S. Economy, Paper presented at the INFORUM World Conference.

Sakellaris, P. \& Wilson, D. J. (2002) Quantifying Embodied Technological Change, ECB Working Paper 158 (Frankfurt, European Central Bank). 
Scherer, F.M. (1999) New Perspectives on Economic Growth and Technological Innovation (Washington, D.C., Brookings Institution Press).

Smith, A. (1937) An Inquiry into the Nature and Causes of the Wealth of Nations (New York, Modern Library).

Wilson, D. J. (2000) Estimating Returns to Scale: Lo, Still No Balance, Journal of Macroeconomics, 22, pp. 285-314.

Wilson, D. J. (2001) Capital-Embodied Technological Change: Measurement and Productivity Effects, PhD Dissertation (University of Maryland).

Wilson, D. J. (2002) Is Embodied Technology the Result of Upstream R\&D? Industry-Level Evidence, Review of Economic Dynamics, 5, pp. 342-362. 


\section{Table 1 - Estimates of Embodied Technological Change}

$\underline{\text { Sector }}$

Food \& Tobacco

Manufacturing

Textiles and knitting

Apparel

Paper

Printing \& publishing

Chemicals

Petroleum refining \& Fuel Oil

Rubber \& Plastic products

Shoes \& leather

Lumber

Furniture

Stone, clay \& glass

Primary metals

Metal products

Industrial Equipment, except computers \& office equipment

Computers \& other office equipment

Electrical equipment except communications and elec. components

Communication equipment

Electronic components

Motor vehicles \& parts

Non-motor vehicle transportation equipment

Scientific Instruments

Other instruments

Miscellaneous manufacturing

\section{Nonmanufacturing}

Agriculture, forestry, and fisheries

0.027

Metal mining

$-0.006$

Coal mining

0.013

Natural Gas and Crude Petroleum extraction

$-0.001$

Non-metallic mining

Construction

Railroads

Air transport

Other transportation

Communication services

Electric utilities

Gas utilities, and water and sanitary services

Wholesale trade

Retail trade, and restaurant and bars

0.026

0.024

0.109

0.058

0.112

0.056

0.033

0.066

0.044

0.065

Finance and Insurance

0.065

Real Estate

0.061

Hotels, and personal and repair services (exc. auto)

0.078

Business services

Automobile services

0.063

Movies and amusement parks

0.037

Medical services

0.062

Education, social services, membership organizations
0.062 
Table 2. Guide to Alternative Specifications for Labor Productivity Equations

\begin{tabular}{l|l}
\hline \multicolumn{1}{c|}{ Description } & \multicolumn{1}{c}{ Equation } \\
\hline $\begin{array}{l}\text { A. Standard Cobb-Douglas Production } \\
\text { Function in logs. }\end{array}$ & $\log (q / \ell)=b_{0}+(\beta-1) \log (\ell)+\alpha \log (j)+\eta \log (s)$ \\
\hline $\begin{array}{l}\text { B. Same as (A) but adjusting to control } \\
\text { for unobserved variation in capital } \\
\text { utilization using the energy-capital ratio } \\
\text { (with elasticity } \tau \text { ) }\end{array}$ & $\log (q / \ell)=b_{0}+\left(\frac{\beta-1}{\beta}\right) \log (q)+\left(\frac{\alpha(\tau-1)}{\beta \tau}\right) \log (j)+\left(\frac{\eta(\tau-1)}{\beta \tau}\right) \log (s)+\left(\frac{\alpha+\eta}{\tau}\right) \log (e)$ \\
\hline $\begin{array}{l}\text { C. Same as (A) but with constant returns } \\
\text { to scale (RTS) imposed. This equation is } \\
\text { derived by setting } \beta+\theta+\alpha+\eta=1 .\end{array}$ & $\log (q / \ell)=b_{0}+\alpha \log (j / \ell)+\eta \log (s / \ell)$ \\
\hline $\begin{array}{l}\text { D. Same as (A) but with constant RTS } \\
\text { and adjusting for utilization using } \\
\text { energy. }\end{array}$ & $\log (q / \ell)=b_{0}+\left(\frac{\alpha(\tau-1)}{\tau}\right) \log (j / \ell)+\left(\frac{\eta(\tau-1)}{\tau}\right) \log (s / \ell)+\left(\frac{\alpha+\eta}{\tau}\right) \log (e / \ell)$ \\
\hline $\begin{array}{l}\text { E. Current IDLIFT equation. Note: qup } \\
\text { and qdown are defined in equation (5). }\end{array}$ & $\log (q / \ell)=b_{0}+a_{1}^{*} t_{1}+a_{2}^{*} t_{2}+a_{3}^{*} q u p+a_{4}^{*} q d o w n$ \\
\hline
\end{tabular}

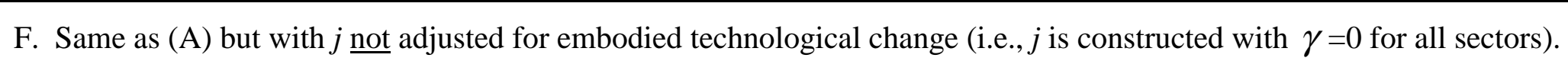

G. Same as (B) but with $j$ not adjusted for embodied technological change (i.e., $j$ is constructed with $\gamma=0$ for all sectors).

H. Same as (C) but with $j$ not adjusted for embodied technological change (i.e., $j$ is constructed with $\gamma=0$ for all sectors).

I. Same as (D) but with $j$ not adjusted for embodied technological change (i.e., $j$ is constructed with $\gamma=0$ for all sectors).

$\mathrm{C}_{+ \text {gap }}$. Same as (C) but include qup and $\quad \log (q / \ell)=b_{0}+\alpha \log (j / \ell)+\eta \log (s / \ell)+a_{3} \cdot q u p+a_{4} \cdot q d o w n$ qdown to control for utilization. 
Table 3. Summary of Results from Estimating Alternative Productivity Equations

\begin{tabular}{|c|c|c|c|c|c|c|c|c|c|}
\hline \multirow[b]{2}{*}{ Specification } & \multicolumn{5}{|c|}{ Average } & \multicolumn{4}{|c|}{ Percent of Industries for which estimate is positive } \\
\hline & Adjusted $\mathrm{R}^{2}$ & $\alpha$ & $\beta$ & $\eta$ & $\tau$ & $\alpha$ & $\beta$ & $\eta$ & $\tau$ \\
\hline A & 0.869 & 0.186 & 0.701 & 0.115 & N/A & 79.6 & 87.0 & 50.0 & N/A \\
\hline $\mathrm{B}$ & 0.911 & 0.231 & 0.565 & 0.299 & 1.438 & 57.4 & 85.2 & 72.2 & 88.9 \\
\hline $\mathrm{C}$ & 0.802 & 0.217 & 0.631 & 0.152 & N/A & 79.6 & 90.7 & 51.9 & N/A \\
\hline $\mathrm{D}$ & 0.876 & 0.268 & 0.474 & 0.257 & 1.161 & 64.8 & 88.9 & 72.2 & 81.5 \\
\hline $\mathrm{E}$ & 0.849 & N/A & N/A & N/A & N/A & N/A & N/A & N/A & N/A \\
\hline $\mathrm{F}$ & 0.855 & 0.184 & 0.732 & -0.005 & N/A & 81.5 & 85.2 & 53.7 & N/A \\
\hline $\mathrm{G}$ & 0.897 & 6.492 & 0.617 & -6.113 & 3.214 & 64.8 & 79.6 & 68.5 & 75.9 \\
\hline $\mathrm{H}$ & 0.782 & 0.243 & 0.595 & 0.162 & N/A & 85.2 & 85.2 & 57.4 & N/A \\
\hline I & 0.863 & 0.101 & 0.479 & 0.420 & -0.394 & 70.4 & 85.2 & 68.5 & 74.1 \\
\hline $\mathrm{C}_{\text {+gap }}$ & 0.813 & 0.223 & 0.587 & 0.190 & N/A & 79.6 & 90.7 & 61.1 & N/A \\
\hline $\mathrm{C}_{+\mathrm{t}}$ & 0.866 & 0.010 & 0.816 & 0.174 & N/A & 51.9 & 92.6 & 63.0 & N/A \\
\hline $\mathrm{C}_{+\mathrm{gap},+\mathrm{t}}$ & 0.867 & 0.082 & 0.743 & 0.175 & N/A & 59.3 & 92.6 & 57.4 & N/A \\
\hline
\end{tabular}




\section{Table 4. Mixed Empirical-Monte Carlo Results}

\begin{tabular}{|c|c|c|c|c|}
\hline Coefficient & True value & Mean Estimate & Std. Deviation & Estimated Bias \\
\hline$c^{0}$ & 2 & 1.99092 & 0.23680 & -0.00908 \\
\hline$c^{l}$ & 0.01 & 0.00968 & 0.00842 & -0.00032 \\
\hline$\alpha$ & 0.17 & 0.18120 & 0.28050 & 0.0112 \\
\hline$\eta$ & 0.16 & 0.15852 & 0.03292 & -0.00148 \\
\hline$b^{0}$ & 0.1 & 0.10118 & 0.35719 & 0.00118 \\
\hline$b^{l}$ & -0.1 & -0.08530 & 0.37322 & 0.0147 \\
\hline
\end{tabular}




\section{Table 5. Specification Choice}

\begin{tabular}{|c|c|c|}
\hline Specification & Number of industries & Number requiring soft constraints \\
\hline C' $^{\prime}$ & 19 & 18 \\
\hline C' $^{\prime \prime}$ & 27 & 25 \\
\hline E & 4 & 2 \\
\hline X & 4 & 4 \\
\hline Total & 54 & 49 \\
\hline
\end{tabular}


Figure 1, Gridsearch Results of Matching FRB Physical Depreciation Patterns

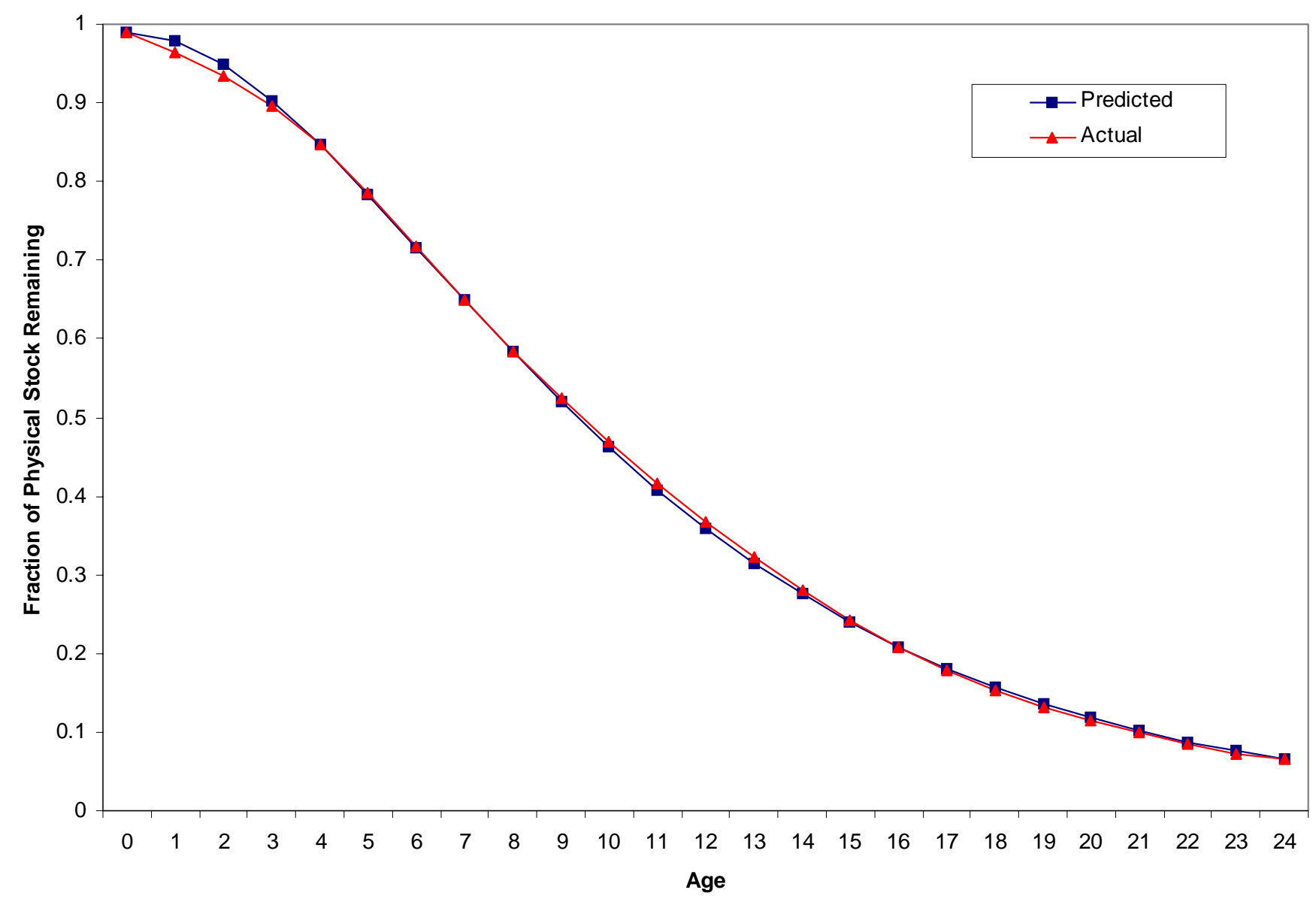


Figure 2, Real GDP

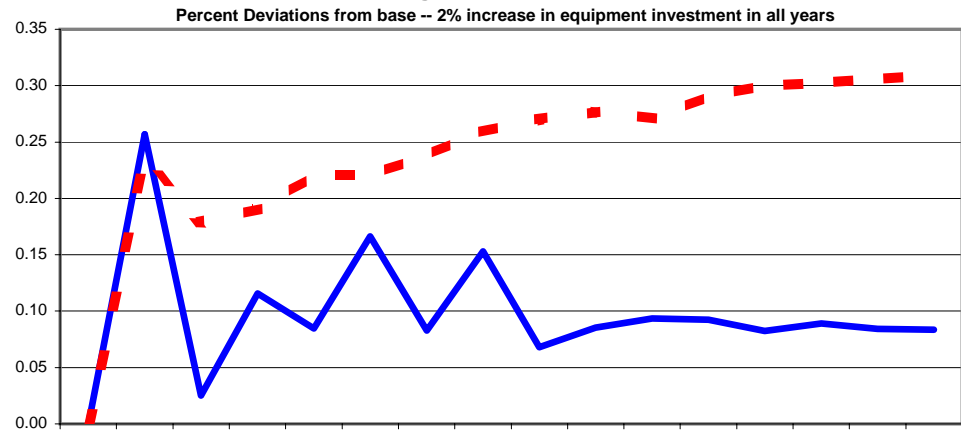

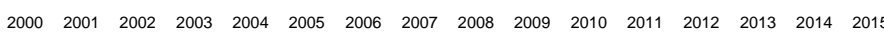
- Old Model

Figure 4, GDP Deflator

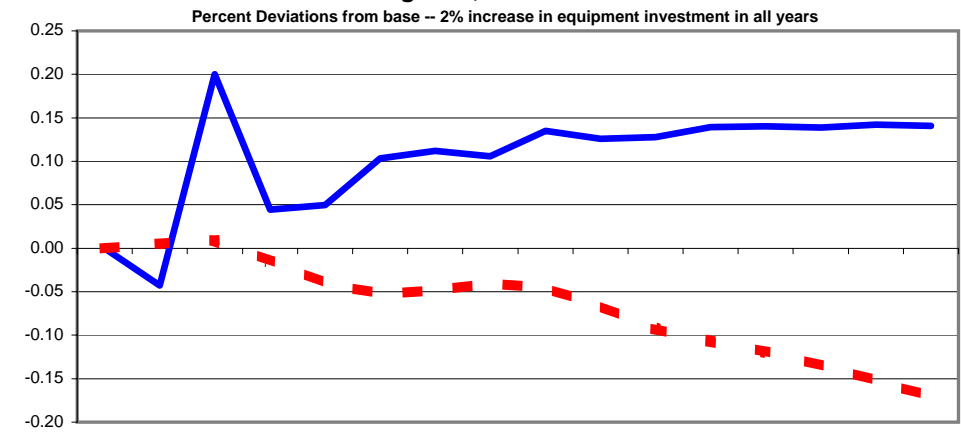

$20002001200220032004 \quad 2005 \quad 2006 \quad 20072008200920102011 \quad 2012 \quad 2013 \quad 2014 \quad 2015$ Oold Model $\quad$ New Model
Figure 3, Nominal GDP

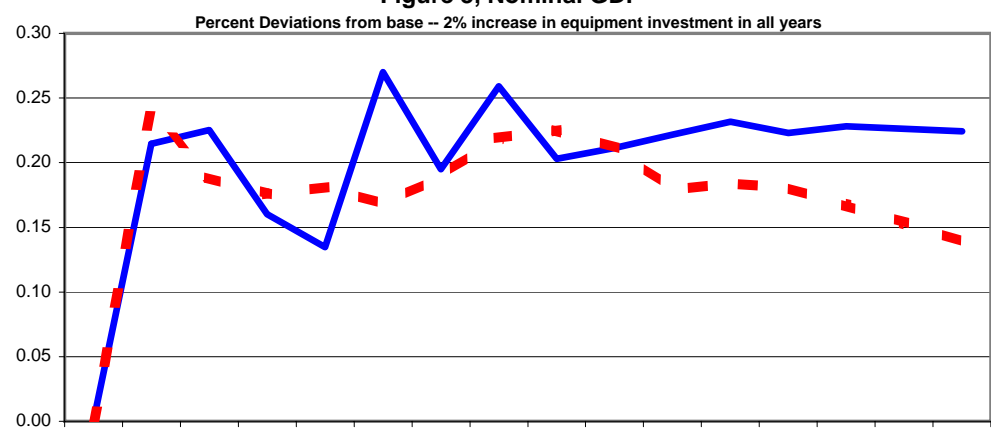

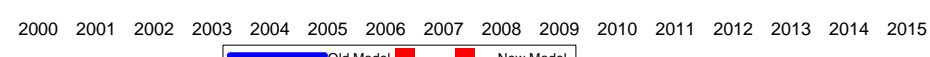
Old Model $\quad$ New Model

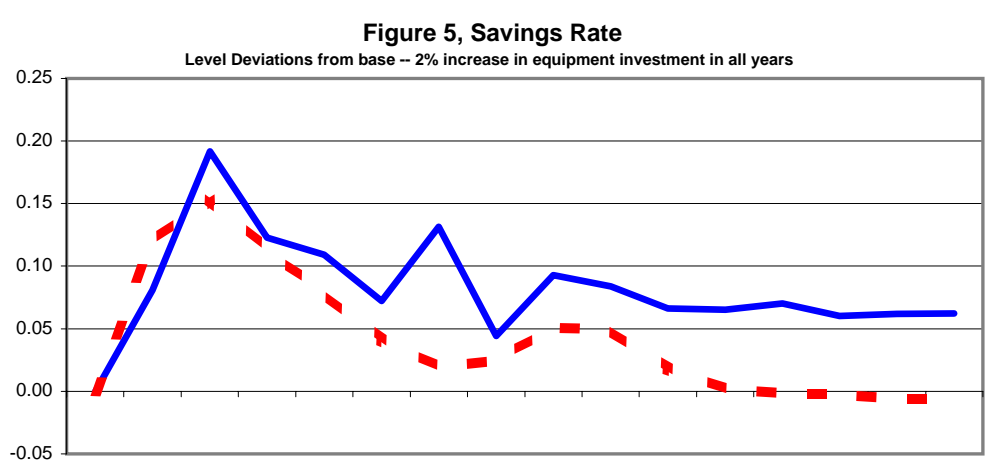

2000200120022003200420052006200720082009201020112012201320142015 Cold Model $=$ New Model 
Figure 6, Unemployment Rate

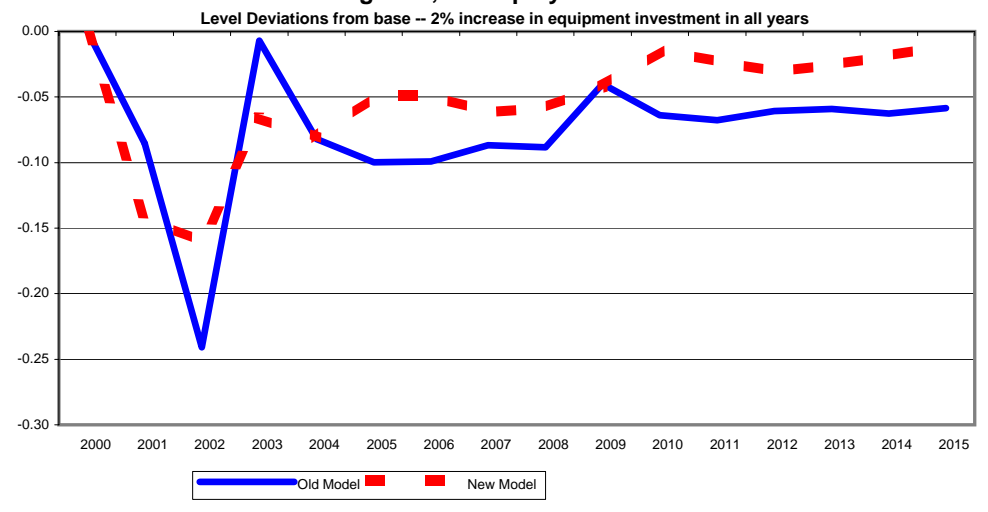

Figure 8, Labor Productivity

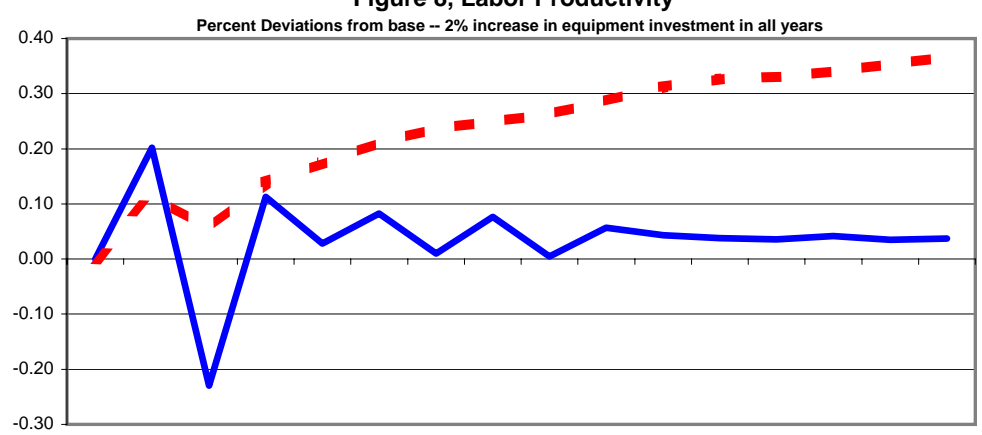

$200020012002200320042005 \quad 20062007200820092010201120122013 \quad 2014 \quad 2015$ Old Model
Figure 7, Total Private Employment

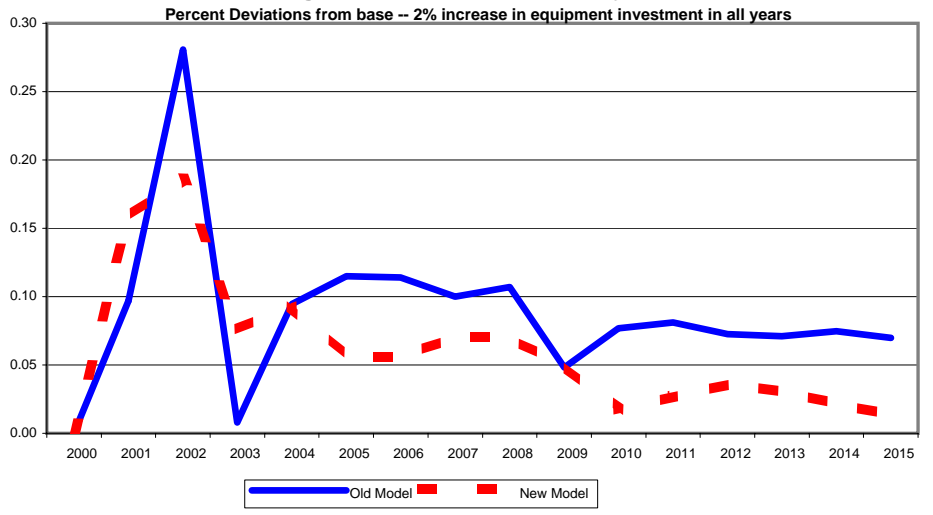


Figure 9, Real GDP

Percent Deviations from base -- 10\% increase in equipment investment in 2001

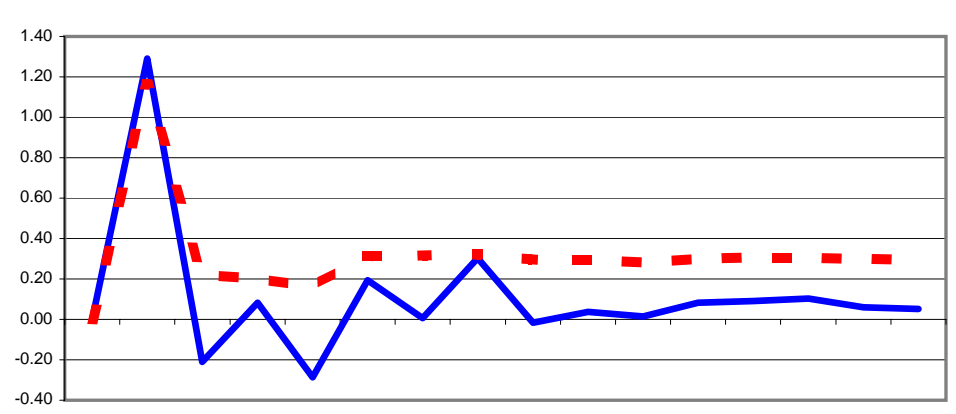

$2000200120022003 \quad 2004 \quad 2005 \quad 2006 \quad 2007 \quad 2008 \quad 2009 \quad 2010 \quad 2011 \quad 2012 \quad 2013 \quad 2014 \quad 2015$ Oold Model $\quad$ New Model

Figure 11, GDP Deflator Percent Deviations from base - $10 \%$ increase in equipment investment in 2001

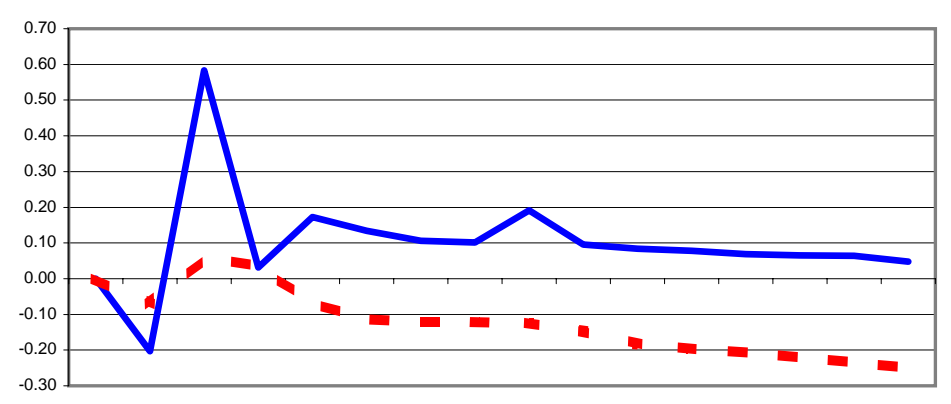

$2000200120022003 \quad 2004 \quad 20052006 \quad 2007 \quad 200820092010201120122013 \quad 2014 \quad 2015$ Old Model 1
Figure 10, Nominal GDP (n)

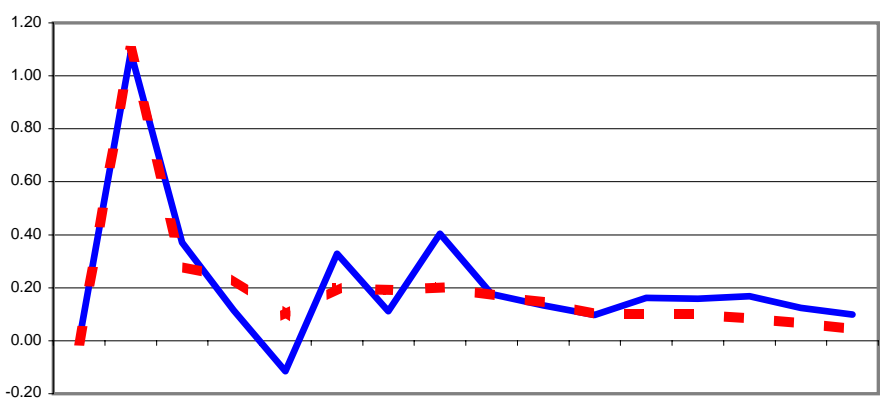

$2000200120022003200420052006 \quad 200720082009201020112012 \quad 20132014 \quad 2015$ Old Model $\mathbf{\square}$ New Model

Figure 12, Savings Rate Percert Devtrost in 200

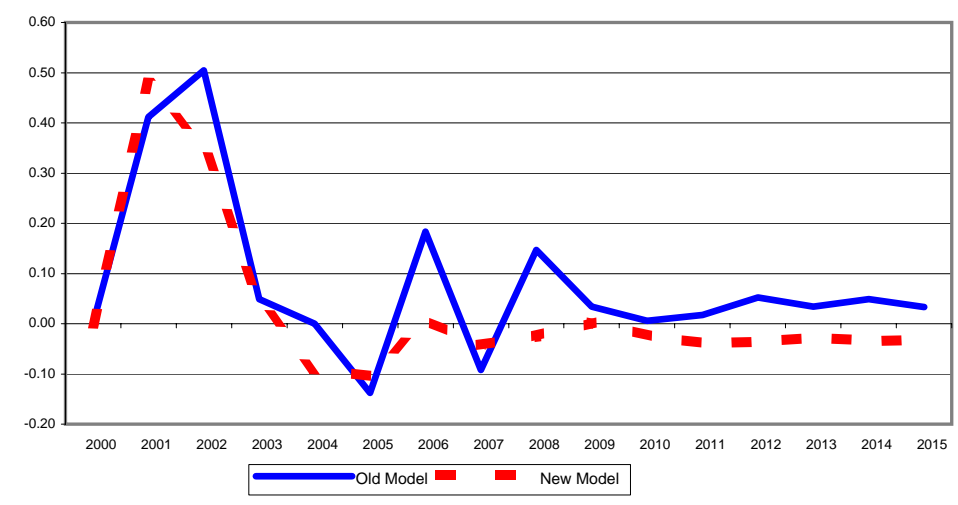


Figure 13, Unemployment Rate

Level Deviations from base -- 10\% increase in equipment investment in 2001

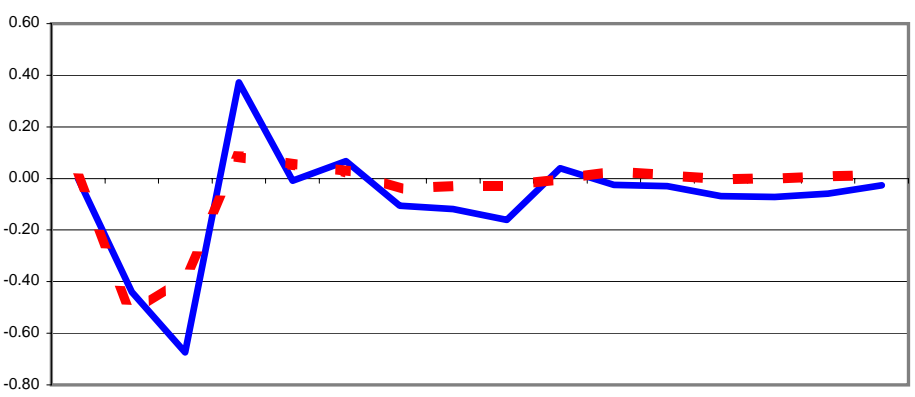

$\begin{array}{llllllllllllllll}2000 & 2001 & 2002 & 2003 & 2004 & 2005 & 2006 & 2007 & 2008 & 2009 & 2010 & 2011 & 2012 & 2013 & 2014 & 2015\end{array}$ Old Model New Model

Figure 15, Labor Productivity

Percent Deviations from base -- 10\% increase in equipment investment in 2001

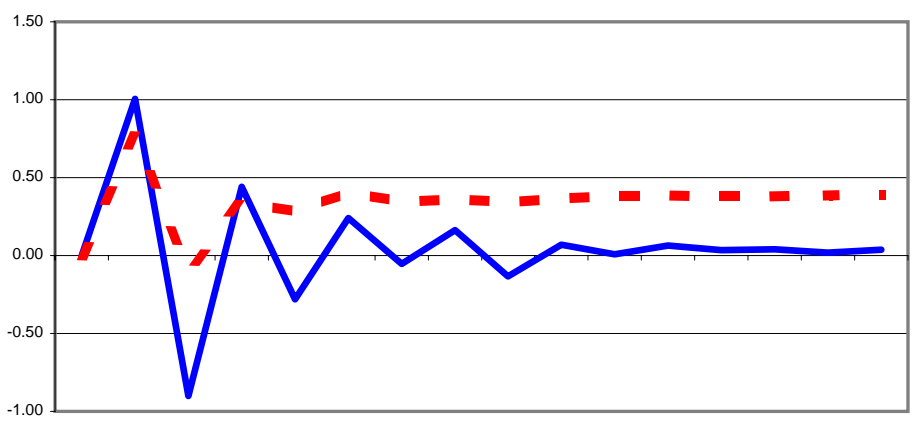

$\begin{array}{llllllllllllllll}2000 & 2001 & 2002 & 2003 & 2004 & 2005 & 2006 & 2007 & 2008 & 2009 & 2010 & 2011 & 2012 & 2013 & 2014 & 2015\end{array}$ Old Model New Model
Figure 14, Total Private Employment

Percent Deviations from base -- 10\% increase in equipment investment in 2001

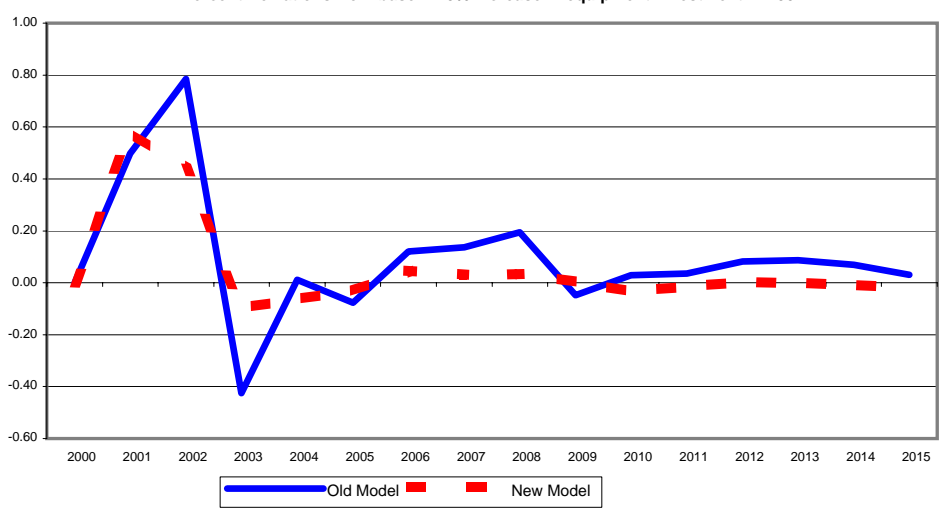

Figure 16, Equipment Capital

Percent Deviations from base -- $10 \%$ increase in equipment investment in 2001

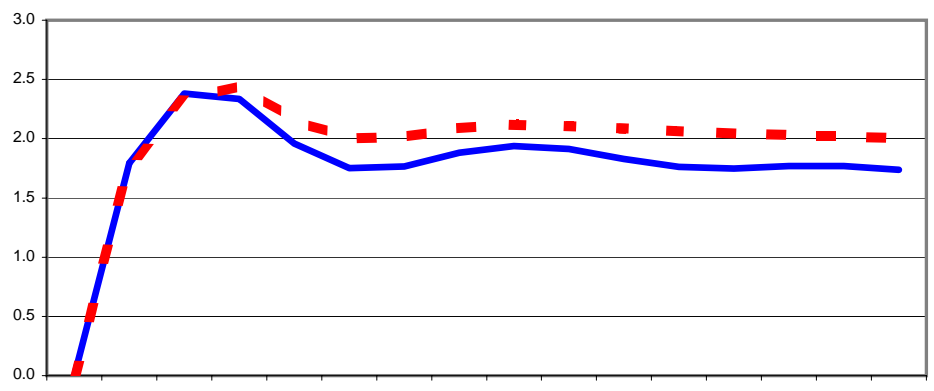

$\begin{array}{llllllllllllllll}2000 & 2001 & 2002 & 2003 & 2004 & 2005 & 2006 & 2007 & 2008 & 2009 & 2010 & 2011 & 2012 & 2013 & 2014 & 2015\end{array}$ Old Model $\square$ New Model 